\title{
Malnutrition and its determinants among older adults people in Addis Ababa, Ethiopia
}

Tadele Abate ${ }^{1}$, Berhanu Mengistuㄹ ${ }^{2}$ Asmamaw Atnafu ${ }^{2}$ and Terefe Derso ${ }^{2^{*}}$

\begin{abstract}
Background: In Ethiopia, malnutrition among older adults is under detected and, neglected area because the entire problem related with aging considered as fate of aging. Also, older adults are often omitted from public health research. Literatures are scarce in Ethiopia; there is limited information in the current study area among older adults using Min Nutritional Assessment (MNA). Therefore, this paper investigated the prevalence of malnutrition and its predictors among older adults people aged 65 years or above in Addis Ababa, Ethiopia.

Methods: A community-based cross-sectional study was employed from January 1 to march 30, 2020 in Addis Ababa. Nutritional status of the older adults was measured by using Min nutritional assessment (MNA). Data from 662 older adults were collected through face to face interviews using a structured questionnaire. Bivariable and multivariable logistic regression analysis was done to identify factors associated with malnutrition.

Result: The prevalence of malnutrition among older adults was found to be 26.6\%[95\% Confidence interval (Cl): 22.8, 30.1]. Depression [Adjusted Odds Ratio $(A O R)=7.57$ 95\%Cl: 5.01, 11.45], being poor [AOR $=1.95$ 95\% Cl: 1.166, 3.25], occupation; daily laborer and guard [AOR $=2.7895 \% \mathrm{Cl}: 1.12,7.17]$ and being old old [AOR $=2.6295 \% \mathrm{Cl}: 1.62$, 4.25] were significantly associated with the higher odds of malnutrition.

Conclusion: This study illustrated that considerably high proportion of older adults were malnourished in Addis Ababa. Socio-economic characteristics and depression were significantly associated with malnutrition. Therefore, nutritional and social support activities are essential for older adults, particularly of those who are socioeconomically disadvantaged and advanced age. In addition, regular nutritional screening and management as well as behavioral interventions should be strengthened as a pillar component of therapeutic interventions. Specific nutritional requirements, at later stages of life is changing, and with the population aged over 65 years increasing in low-income countries like Ethiopia, the research in this field is likely to increase further.
\end{abstract}

Keywords: Malnutrition, Determinants, Older adults

\footnotetext{
* Correspondence: dersotere@gmail.com

${ }^{2}$ Department of Health Systems and Policy, Institute of Public Health, College of Medicine and Health Sciences, University of Gondar, Gondar, Ethiopia Full list of author information is available at the end of the article
}

\section{BMC}

(c) The Author(s). 2020 Open Access This article is licensed under a Creative Commons Attribution 4.0 International License, which permits use, sharing, adaptation, distribution and reproduction in any medium or format, as long as you give appropriate credit to the original author(s) and the source, provide a link to the Creative Commons licence, and indicate if changes were made. The images or other third party material in this article are included in the article's Creative Commons licence, unless indicated otherwise in a credit line to the material. If material is not included in the article's Creative Commons licence and your intended use is not permitted by statutory regulation or exceeds the permitted use, you will need to obtain permission directly from the copyright holder. To view a copy of this licence, visit http://creativecommons.org/licenses/by/4.0/ The Creative Commons Public Domain Dedication waiver (http://creativecommons.org/publicdomain/zero/1.0/) applies to the data made available in this article, unless otherwise stated in a credit line to the data. 


\section{Background}

Old age is defined as people aged 65 years or above [1]. In fact ageing is an irreversible biological phenomenon [2]. Particularly, older adults are highly vulnerable to malnutrition [3]. Globaly, about 13-78\% of the older adults are suffering from malnutrition [4] . If it is not prevented or treated in time, it could increase morbidity and mortality rates, thus becoming a problem of great personal, family and socio-health significance [5].

So far, malnutrition in older adults remains under detected, under-treated, under-resourced and leads to further weight loss, increased infections and delay in recovery from illness as well as increased hospital admissions and length of stay [6]. Obviously, malnutrition is multi-factorial, it could be due to inadequate food intake, illness or both that causes increased nutrient loss, poor nutrient absorption or both [7]. Previous studies have shown that socio-cultural, health and socioeconomic characteristics are main significant determinants of malnutrition [8, 9]. High odds of malnutrition has been documented among female, older age [10], unmarried [11], illiterate [12], low income [13], and living alone [12] older adults. Moreover, reduction of income and physical in capability in older adults increases vulnerability to food insecurity, which in turn predisposes to malnutrition [8]. Geographic and psychosocial concerns, can also affect dietary behaviors and nutritional status [9].

Population aging is an emerging challenge in Africa [14]. Despite the increasing number of older adults, there has been little effort to fulfill their health and nutritional needs, and therefore they seek a great attention in Ethiopia [15, 16]. Ethiopia has been implementing policy, program and strategies such as; Food and Nutrition program (FNP), Immunization and Health Sector Transformation Plan i.e. focusing to improve children, adolescents and maternal health and nutrition [17-19]. However, malnutrition among older adults is underdetected and neglected area because the entire problem related with aging considered as fate of aging. Also literatures are scarce in Ethiopia; there is a limited information in the current study area among older adults using Min nutritional assessment (MNA) tool recommended by the European Society for Clinical Nutrition and Metabolism (ESPEN) and fitted for Ethiopian older adults $[20,21]$. Investigating the prevalence and determinants of malnutrition in a disadvantaged segment of population is of a crucial importance to develop strategies to address the problem and provide holistic support for the older adults. Therefore, this study was aimed to assess prevalence of malnutrition and its associated factor among older adults in Addis Ababa, Ethiopia.

\section{Methods}

\section{Study setting and design}

A community based cross sectional study was conducted from January 1 to March 30, 2020 among older adults aged 65 years or above in Addis Ababa, Ethiopia. Addis Ababa is the capital city of Ethiopia with an area of 530 $\mathrm{km}^{2}$. Addis Ababa city administration is divided into 10 administrative sub-cities. According the Ethiopian Central Statistical Agency (CSA) data, the estimated total population is of 3.4 million; of these $116,549(3.4 \%)$ were estimated to be older adults [22].

\section{Study population and sampling procedure}

All older adults aged 65 years or above who lived in Addis Ababa for at least 6 months were included in the study. Sample size was computed using epi-info version 7.6 considering the following assumptions; percent of outcome in the unexposed group $=14.8$ and Crude Odds Ratio $(\mathrm{COR})=2.3$ as of malnutrition among older adults in northwest, Ethiopia [23]; 95\% level of confidence, 1:1 ratio and $80 \%$ power. Considering a10\% contingency for non-respondents and using design effect of 2, minimum sample size of 682 was obtained. Regarding sampling technique, the total lists of older adults were obtained from health extension workers, Addis Ababa health office. First, three (3) sub cities (Bole, Yeka and Lideta) were selected randomly from the 10 sub cities. The numbers of older adults in each randomly selected sub cities were proportionated to the sample size. Then, older adults were selected by systematic random sampling technique. For households with multiple older adults individuals, one older adult was selected randomly.

\section{Data collection procedures and variable measurement}

An interviewer administered structured questionnaire was used to collect socio-demographic, financial support, alcohol consumption, cigarette smoking, and health and nutrition characteristics of older adults through house to house visit. Nutritional status of the older adults was measured by using Min nutritional assessment (MNA) tool [24] as recommended by the European Society for Clinical Nutrition and Metabolism (ESPEN) [20], and the MNA has been standardized for older adults in the other part Ethiopia [21]. The Mini nutritional assessment tool consists of 18-items grouped into four: general assessment (lifestyle, medication, stress, mobility, neuropsychological problems and skin lesion), subjective assessment (perceived health and nutritional status), dietary assessment (number of meals, food and fluid intake, and mode of feeding) and anthropometric assessment (weight, height, arm and calf circumference and weight loss) [24]. The data was collected by 10 trained diploma nurses, and the supervisors were three BSc holder health 
officers. Prior to the data collection, 2 day training was given on data collection tools, ethics and approach in the interviewing techniques.

Weight of the study participants was measured using a beam balance to the nearest $0.1 \mathrm{Kg}$ without shoes and all heavy clothing, including jackets, jerseys, and belts. Weighing scale was checked against a standard weight for its accuracy on daily basis. Calibration was performed before weighing each study participant by setting it to zero. Height of the study participants was taken using a seca vertical height scale standing upright in the middle of the board. Participants were asked to take off their shoes and stand in Frankfurt plane (stand erect, and look straight in horizontal plain). The occipital (back of head), shoulder blades, buttocks, and heels were touched measuring board and height was record to the nearest $0.01 \mathrm{~cm}$.

To determine malnutrition, first the MNA score was ranged from 0 to 30 points. Using the MNA score, malnutrition was defined by MNA score less than 17 points. Furthermore, nutrition status was stratified: normal nutritional status (24-30 points), risk of malnutrition (1723.5 points) and malnutrition (points less than 17) [24].

Geriatric Depression Scale item 15 (GDS-15) was used to assess depression among older adults suggested by the Royal College of Physicians, the British Geriatric Society and the Royal College of general practitioners. Thus, depression was defined using a cut-off point greater than or equal to five [25]. Another variable, wealth status was computed based on the possession of household assets (i.e., refrigerator, sofa, bicycle, television, radio, and mobile telephone) was used as a proxy for socio-economic status using principal component analysis. Finally, wealth index was ranked into three; poor, medium and rich. The last variable, old age was categorized into three; young old (65-74 years old), middle old (75-84 years old) and old old ( $>=85$ years old) [1]. To maintain the quality of data: regular supervision, spot-checking, and reviewing the completed questionnaire on daily basis was carried out by the investigators and supervisors.

\section{Data analysis}

Data was cleaned and entered into the Epi-Data version 4.6 statistical software and exported to SPSS version 20 statistical package for analysis. Before analysis, missing values and outliers were checked and corrected by cross checking with original questionnaire. Frequencies and proportions were used to summarize variables. Besides, frequencies and proportions of each variable were presented using tables and figures. Association between malnutrition and each categorical variable was assessed using the binary logistic regression model. Variables such as age, head of the house hold, educational status, occupation, depression, marital status and wealth index which were significant at $P$-value $<0.2$ in the bi-variable analysis were entered into the multivariable analysis. Accordingly, age, occupation, depression, wealth index, head of the household, marital status and educational status were adjusted in the binary logistic regression model. The significance of association was determined at a $P$-value of $<0.05$ in the multivariable analysis, while the strength of association was measured by Adjusted Odds Ratio with 95\% confidence interval.

\section{Results}

\section{Socio demographic characteristics}

A total of 662 older adults were included in this study (with a response rate of 97\%). The majority of study participants were in the age range between 65 and 74 years $(72.2 \%)$ and retired $(73.6 \%)$. Half of older adults had no formal education (52\%) and lived with their children (54.1\%)(Table 1).

\section{Depression}

The prevalence of depression was found to be $27.64 \%$.

\section{Prevalence of malnutrition among elderly people}

The prevalence of malnutrition among older adults was $26.6 \%$ [95\% CI, 22.8, 30.1]. More than half of study participants had eaten three full meals a day (59.52\%) and had no decrease in food intake (56.34\%) for the past 3 months. On the other hand, majority of older adults (82.93\%) did not consume selected consumption marker of protein like dairy product (milk, cheese and yoghurt), legumes, egg and poultry every day (Table 2).

\section{Factors associated with malnutrition among elderly people}

The result of multivariable analysis revealed that depression, occupation, wealth index and age were independently and significantly associated with malnutrition. The likelihood of being malnourished was higher among older adults with old old aged $[\mathrm{AOR}=2.94,95 \% \mathrm{CI}$ : $1.29,6.67]$ and poor wealth index $[\mathrm{AOR}=1.95,95 \% \mathrm{CI}$ : $1.66,3.25]$ compared to their counterparts. The study also found that the odds of malnutrition was 7.5 times higher among older adults who had depression $[\mathrm{AOR}=$ 7.57, 95\% CI: 5.01, 11.45] compared to older adults who had no depression. Furthermore, occupation; daily laborer and guard $[\mathrm{AOR}=2.77,95 \% \mathrm{CI}: 1.09,7.06]$ were significantly associated with higher odds of malnutrition among older adults (Table 3).

\section{Discussion}

Malnutrition is a significant public health problem especially, in resource-limited setting like Ethiopia where 
Table 1 Socio-demographic characteristics of older adults in Addis Ababa

\section{Socio-demographic \\ Age \\ young old (65-74 years) \\ middle old (75-84 years) \\ old old ( $>=85$ years) \\ Sex of the respondent}

Female

Male

Religion of the respondent

Orthodox

Muslim

Protestant

Catholic

Family size

$<=5$

$>=6$

Marital status

Single/divorce/widowed

Married

\section{Education status}

No formal education

Primary education

Secondary to higher education

\section{Occupation of the responden}

Retired

daily laborer and guard

Merchant (self-employed)

The main sours of financial support

Family support

Pension

Organization or NGO support

\section{Head of the house hold}

Father

Mother

Children/relatives

With whom respondent lives

With children

With partner

Alone

Others ${ }^{\mathrm{a}}$

Wealth index

Poor

Middle

Rich

Alcohol consumption
Frequency (n)

Percent (\%)

511 
Table 1 Socio-demographic characteristics of older adults in Addis Ababa (Continued)

\begin{tabular}{lll}
\hline Socio-demographic & Frequency $(\mathbf{n})$ & Percent $(\%)$ \\
\hline Yes & 62 & 9.4 \\
No & 600 & 90.6 \\
Smoking cigarette & & 0.5 \\
Yes & 3 & 99.5 \\
No & 659 & \\
\hline
\end{tabular}

${ }^{a}$ Relatives

food insecurity prevail [3, 4, 25]. However, malnutrition in vulnerable groups such as older adults have usually been ignored [26, 27]. Our study is the one to focus on malnutrition of older adults and has a crucial importance to develop strategies to address malnutrition and provide holistic support for the older adults. This finding show that more than one-fourth $(26.6 \%)$ of the older adults were malnourished. Moreover, depression, occupation, wealth index and age were independent predictors of malnutrition. The current finding was consistent with local studies from Debre Markos town, Northwest Ethiopia (22.7\%) [28] and Hawassa city, Southern Ethiopia (28.3\%) [21].

However, the current finding was higher than local finding reported from Aykele town, Amhara region, Ethiopia (17.6\%). The discrepancy might be due to the difference of nutritional assessment methods, the former study assessed nutritional status based on Body Mass Index (BMI); whereas the current study assessed nutritional status based on Mini nutritional assessment which is a better way to identify nutritional disorder in older adults $[24,29]$. Since BMI does not take into account the structure of the body or the percentage and distribution of adipose tissue, both of which change as a person ages [30] and also does not reflect changes that may occur due to sarcopenia (loss of skeletal muscle mass) or decrease in stature (osteoporosis, degenerative changes in the vertebrae and vertebral discs thinning) [31]. Thus, $\mathrm{BMI}$ is masking important weight changes and resulting in the failure to recognize malnutrition in time [24]. This implies that MNA is a better proxy than BMI to determine the nutritional status of older adults [29]. Similarly, a higher prevalence of malnutrition was reported in this study compared to previous studies reported from South Africa (5.5\%) [32],Sire Lanka (13.6\%) [33] and Brazil (18.8\%) [34]. This might be due to the difference in the living standards and socioeconomic status like economic power of the older adults. The present study was done among older adults living in low income country compared to the earlier studies. This could explain lower food purchasing power of older adults, which in turn results in the consumption of undiversified food items, and limit their dietary intakes. Low dietary intake may increase the risk of malnutrition. Also, cultural difference including religious differences among older adults could be another possible reason.

The result the adjusted analysis demonstrated that the odds of malnutrition were higher among oldest old (aged 75 years old or above) older adults as compared to young old (aged 65-74 years old). This finding was confirmed by a local studies done in Debre Markose [28] and Gondar [23], Ethiopia which states that oldest old were more likely to be malnourished than young old people. Obviously, increased age puts older adults in a catabolic state i.e. body decomposition [35]. The risk of malnutrition is higher as their functional status is deteriorated possibly because of age increases and chronic co-morbidities such as respiratory disease, arteritis, and dementia. Impaired mobility and co-morbidities are known to impair appetite thereby food intake of the older adults [36].

This study also illustrated that depression was significantly associated with higher likelihood of malnutrition. Also, higher odds of malnutrition were reported among depressed older adults from studies done in South Africa, India and Netherland [2, 32, 37]. This might be due to depression negatively influences the appetite, food in-take and reduced energy in-take, and this can lead to weight loss and increase the risk of malnutrition [38].

The likelihood of malnutrition was increased by 1.94 folds among older adults in the poor wealth category. This finding is congruent with the study done in Northwest Ethiopia [23] and Northern Italy [13]. Thus, in poor households food consumption is reduced because of economic reasons, this may severely impact the physical and health status of the individual [39]. Particularly, older adults with poor socioeconomic status might not afford nutrient dense and protein rich food, as a result cereal-based monotonous diet is common in this group of people which again diminishes their body ability and increases the risk of fat and fat-free loss $[8,13]$.

Finally, this paper showed increased odds of malnutrition among daily laborer and guard older adults compared to merchant (self employed) older adults. The 
Table 2 Nutritional status of older adults in Addis Ababa

\begin{tabular}{|c|c|c|}
\hline Variables & Frequency & Percent (\%) \\
\hline \multicolumn{3}{|l|}{ Malnutrition } \\
\hline Yes & 176 & 26.6 \\
\hline No & 486 & 73.4 \\
\hline \multicolumn{3}{|l|}{ Has food intake declined over the past 3 months } \\
\hline Sever decrease in food intake & 88 & 10.3 \\
\hline Moderate decrease in food intake & 221 & 33.4 \\
\hline No decrease in food intake & 373 & 56.3 \\
\hline \multicolumn{3}{|l|}{ Weight loss during the last 3 months } \\
\hline Weight loss greater than $3 \mathrm{~kg}$ & 61 & 9.2 \\
\hline Dose not know & 335 & 50.6 \\
\hline Weight loss between $1 \mathrm{~kg}$ and $3 \mathrm{~kg}$ & 48 & 7.3 \\
\hline No Weight loss & 218 & 32.9 \\
\hline \multicolumn{3}{|l|}{ Mobility } \\
\hline Bed or chair bound & 22 & 3.3 \\
\hline Able to get out of bed /chair but does not go out & 93 & 14 \\
\hline Goes out & 547 & 82.6 \\
\hline \multicolumn{3}{|c|}{ Has suffered psychological or acute disease in the past 3 months } \\
\hline Yes & 63 & 9.5 \\
\hline No & 599 & 90.5 \\
\hline \multicolumn{3}{|l|}{ Neuropsychological problem } \\
\hline Sever dementia or depression & 23 & 3.5 \\
\hline Mild dementia & 171 & 25.8 \\
\hline No psychological problem & 468 & 70.7 \\
\hline \multicolumn{3}{|l|}{ Body Bass Index (BMI) } \\
\hline BMI less than 19 & 61 & 9.2 \\
\hline BMI 19 to less than 21 & 222 & 33.5 \\
\hline BMI 21 to less than 23 & 276 & 41.7 \\
\hline BMI 23 or greater & 103 & 15.6 \\
\hline \multicolumn{3}{|l|}{ Lives independently (not in nursing home or hospital) } \\
\hline Yes & 662 & 100 \\
\hline No & 0 & 0 \\
\hline \multicolumn{3}{|l|}{ Takes more than 3 prescription drugs per day } \\
\hline Yes & 172 & 26 \\
\hline no & 490 & 74 \\
\hline \multicolumn{3}{|l|}{ Pressure sores or skin ulcers } \\
\hline Yes & 19 & 2.9 \\
\hline No & 643 & 97.1 \\
\hline \multicolumn{3}{|l|}{ How many full meal dose the client eat daily } \\
\hline 1 meal & 11 & 1.7 \\
\hline 2 meal & 257 & 38.8 \\
\hline 3 meal & 394 & 59.5 \\
\hline
\end{tabular}

Selected consumption markers for protein intake

At least one serving of dairy products (milk, cheese, yoghurt) per day

Two or more serving of legumes or eggs per week 
Table 2 Nutritional status of older adults in Addis Ababa (Continued)

\begin{tabular}{|c|c|c|}
\hline Variables & Frequency & Percent (\%) \\
\hline \multicolumn{3}{|l|}{ Meat,fish or poultry every day } \\
\hline If 0 or 1 yes & 549 & 82.9 \\
\hline If 2 yes & 106 & 16 \\
\hline If 3 yes & 7 & 1.1 \\
\hline \multicolumn{3}{|c|}{ Consume two or more serving of fruit or vegetables pre day } \\
\hline No & 607 & 91.7 \\
\hline Yes & 55 & 8.3 \\
\hline \multicolumn{3}{|c|}{ How much fluid (water, juice, coffee, tea, milk..) is consume per day } \\
\hline Less than 3 cups & 303 & 45.8 \\
\hline 3 to 5 cups & 321 & 48.5 \\
\hline More than 5 cups & 38 & 5.7 \\
\hline \multicolumn{3}{|l|}{ Mode of feeding } \\
\hline Unable to eat without assistance & 22 & 3.3 \\
\hline Self -fed with some difficulty & 101 & 15.3 \\
\hline Self - fed without any problem & 539 & 81.4 \\
\hline \multicolumn{3}{|l|}{ Self -view of nutritional status } \\
\hline View self as being malnourished & 89 & 13.4 \\
\hline Is uncertain of nutritional status & 379 & 57.3 \\
\hline View self as having no nutritional problem & 194 & 29.3 \\
\hline \multicolumn{3}{|c|}{ In comparison with other people of the same age, how does the client consider his /her health status } \\
\hline Not as good & 139 & 21 \\
\hline Dose not know & 161 & 24.3 \\
\hline As good & 289 & 43.7 \\
\hline Better & 73 & 11 \\
\hline \multicolumn{3}{|l|}{ Mid -arm circumference (MAC) in cc } \\
\hline MAC less than 21 & 62 & 9.4 \\
\hline MAC 21 to 22 & 208 & 31.4 \\
\hline MAC greater than 22 & 392 & 59.2 \\
\hline \multicolumn{3}{|l|}{ Calf circumference (CC) in cm } \\
\hline CC less than 31 & 281 & 42.4 \\
\hline CC 31 or greater & 381 & 57.6 \\
\hline
\end{tabular}

adverse effect of unemployment on malnutrition mainly operates through its impact on the household economic deprivation. Similarly, most of the older adults in Ethiopia are not empowered compared to the non- older adults, which indirectly influence their economic power to purchase nutritious food.

Limitation: This study addressed an important public health concern, malnutrition. However, the crosssectional nature of this study could not show the causal relationship between the response and explanatory variables. Hence, the study included samples from community; the findings may not be generalizable to those who did live in humanitarian organization like Mekedonia.
Moreover, the study is not free from recall bias as the measurement of dietary issues was relied on memory, nevertheless efforts, such as training of data collectors and supervisors and appropriate probing techniques were used to minimize this bias. Finally, self-reported nature of the questionnaire also limits the external validity of the study.

\section{Conclusion}

This study illustrated that considerably high proportion of older adults were malnourished in Addis Ababa. Socio-economic characteristics (wealth index and occupation) and depression were significantly associated with 
Table 3 Factors associated with malnutrition among older adults in Addis Ababa

\begin{tabular}{|c|c|c|c|c|}
\hline \multirow{2}{*}{$\begin{array}{l}\text { Variable } \\
\text { Age }\end{array}$} & \multicolumn{2}{|c|}{ Malnutrition } & \multirow[t]{2}{*}{ COR $(95 \% \mathrm{Cl})$} & \multirow[t]{2}{*}{ AOR $(95 \% \mathrm{Cl})$} \\
\hline & Yes & No & & \\
\hline young old & 103 & 408 & 1 & 1 \\
\hline middle old & 54 & 64 & $3.34(2.19,5.09)$ & $2.62(1.62,4.25)^{*}$ \\
\hline old old & 19 & 14 & $5.37(2.60,11.08)$ & $2.94(1.29,6.67)^{*}$ \\
\hline \multicolumn{5}{|l|}{ Occupation } \\
\hline Retired & 148 & 339 & $4.20(2.19,8.06)$ & $2.15(0.98,4.38)$ \\
\hline Daily laborer and guard & 17 & 41 & $3.99(1.72,9.25)$ & $2.77(1.09,7.06)^{*}$ \\
\hline Merchant (self-employed) & 11 & 106 & 1 & 1 \\
\hline \multicolumn{5}{|l|}{ Depression } \\
\hline Yes & 110 & 73 & $9.42(6.36,13.97)$ & $7.57(5.00,11.45)^{*}$ \\
\hline No & 66 & 413 & 1 & 1 \\
\hline \multicolumn{5}{|l|}{ Wealth index } \\
\hline Poor & 73 & 154 & $2.25(1.44,3.53)$ & $1.94(1.16,3.25)^{*}$ \\
\hline Middle & 65 & 151 & $2.05(1.3,3.231)$ & $1.66(0.90,2.81)$ \\
\hline Rich & 38 & 181 & 1 & 1 \\
\hline \multicolumn{5}{|l|}{ Head of the house hold } \\
\hline Father & 79 & 239 & 1 & 1 \\
\hline Mother & 89 & 240 & $1.12(.78,1.59)$ & $0.73(0.39,1.38)$ \\
\hline Children/relatives & 8 & 7 & $3.45(1.21,9.83)$ & $1.58(0.40,6.19)$ \\
\hline \multicolumn{5}{|l|}{ Marital status } \\
\hline Married & 66 & 226 & 1 & 1 \\
\hline Divorce/widowed & 110 & 260 & $1.44(1.07,1.06)$ & $1.36(0.87,2.11)$ \\
\hline \multicolumn{5}{|l|}{ Education status } \\
\hline No formal education & 106 & 238 & $1.80(1.00,3.27)$ & $1.63(0.79,3.32)$ \\
\hline Primary education & 54 & 183 & $1.19(0.64,2.24)$ & $1.33(0.64,2.78)$ \\
\hline Secondary to higher & 16 & 65 & 1 & 1 \\
\hline
\end{tabular}

*indicates significant at $p$-Value less than 0.05in the multivariable analysis

malnutrition. Therefore, nutritional and social support activities are essential for older adults, particularly of those who are socio-economically disadvantaged and advanced age. In addition, regular nutritional screening and management as well as behavioral interventions should be strengthened as a pillar component of therapeutic interventions. At last, specific nutritional requirements, at later stages of life is changing, and with the population aged over 65 years increasing in low-income countries like Ethiopia, the research in this field is likely to increase further.

\section{Supplementary Information}

The online version contains supplementary material available at https://doi. org/10.1186/s12877-020-01917-w.

Additional file 1.

\section{Abbreviations}

AOR: Adjusted Odds Ratio; BMI: Body Mass Index; COR: Crude Odds Ratio;

CSA: Central Statistical Agency; ESPEN: European Society for Clinical Nutrition and Metabolism; GDS: Geriatric Depression Scale; MNA: Mini Nutritional Assessment; WHO: World Health Organization

\section{Acknowledgements}

We would like to thank study participants for their willingness to participate in the study. Our appreciation will also go to Addis Ababa Health Bureau for materials support.

\section{Authors' contributions}

TA, TD, BM and AA designed the study, participated in the data collection, performed analysis and interpretation of data and drafted the paper and revised the manuscript. TA BM assisted with the design, approved the proposal, and revised drafts of the paper. TA, TD, BM and AA assisted with the design, approved the proposal, and revised drafts of the paper and prepared and revised the manuscript. All authors read and approved the final manuscript.

Funding

The authors received no specific funding for this work.

Availability of data and materials

Data will be made available upon request to the primary author/ corresponding author. 


\section{Ethics approval and consent to participate}

Prior to data collection, ethical approval was obtained from ethical review committee of Institute of Public Health, College of Medicine and Health Sciences, University of Gondar. Permission letter was also obtained from Addis Ababa Health Bureau. Written informed consent was taken from each study participant after the purpose of the study had been explained. They were informed to withdraw at any time and/or to refrain from responding to questions. Participants also informed that all the data obtained from them would be kept confidential using codes instead of any personal identifiers.

\section{Consent for publication}

Not applicable.

\section{Competing interests}

The authors declare that they have no conflict of interest.

\section{Author details}

'Department of Human Nutrition, Institute of Public Health, College of Medicine and Health Sciences, University of Gondar, Gondar, Ethiopia. ${ }^{2}$ Department of Health Systems and Policy, Institute of Public Health, College of Medicine and Health Sciences, University of Gondar, Gondar, Ethiopia.

Received: 15 June 2020 Accepted: 17 November 2020

Published online: 23 November 2020

\section{References}

1. World Health Organization. Men, ageing and health: Achieving health across the life span. Geneva: World Health Organization; 2001.

2. Lonterman-Monasch S, de Vries OJ, Danner SA, Kramer MH, Muller M. Prevalence and determinants for malnutrition in geriatric outpatients. Clin Nutr. 2013;32(6):1007-11.

3. Bales CW, Johnson MA. Chapter 56, Nutrition in Older adults'a Wolters Kluwer business, vol. 745. 11th ed; 2014

4. Guigoz $\mathrm{Y}$. The mini nutritional assessment $\left(\mathrm{MNA}^{\bullet}\right)$ review of the literaturewhat does it tell us? J Nutr Health Aging. 2006;10(6):466.

5. Stratton RJ. Clinical and economic effects of managing malnutrition. Nutr Hosp. 2012;5(1):87-95.

6. Wilson LMTF. A review and summary of the impact of malnutrition in older people and the reported costs and benefits of interventions; 2013.

7. Demling RH, DeSanti L. Involuntary weight loss and protein-energy malnutrition: diagnosis and treatment; 2001.

8. Hamren K, Chungkham HS, Hyde M. Religion, spirituality, social support and quality of life: measurement and predictors CASP-12 (v2) amongst older Ethiopians living in Addis Ababa. Aging Ment Health. 2015;19(7):610-21.

9. Kaiser MJ, Bauer JM, Ramsch C, Uter W, Guigoz Y, Cederholm T, Thomas DR, Anthony P, Charlton KE, Maggio M, Tsai AC. Validation of the Mini Nutritional Assessment Short-Form (MNA ${ }^{\oplus}$-SF): A practical tool for identification of nutritional status. J Nutr Health Aging. 2009;13(9):782.

10. Cuervo M, García A, Ansorena D, Sanchez-Villegas A, Martínez-González MA, Astiasarán I, Martinez JA. Nutritional assessment interpretation on 22007 Spanish community-dwelling elders through the mini nutritional assessment test. Public Health Nutr. 2009:12(1):82-90.

11. De Morais C, Oliveira B, Afonso C, Lumbers M, Raats M, De Almeida MD. Nutritional risk of European elderly. Eur J Clin Nutr. 2013;67(11):1215-9.

12. Rodriguez-Tadeo A, Wall-Medrano A, Gaytan-Vidaña ME, Campos A, OrnelasContreras M, Novelo-Huerta HI. Malnutrition risk factors among the elderly from the US-Mexico border: the "one thousand" study. J Nutr Health Aging. 2012;16(5):426-31.

13. Timpini A, Facchi E, Cossi S, Ghisla MK, Romanelli G, Marengoni A. Selfreported socio-economic status, social, physical and leisure activities and risk for malnutrition in late life: a cross-sectional population-based study. J Nutr Health Aging. 2011;15(3):233-8.

14. United Nation (UN). Department of Economic and Social Affairs, Population Division. Population facts: United Nation (UN); 2012. Report no: 2012/4.

15. World Health Organization. World health statistics 2016: monitoring health for the SDGs sustainable development goals. Geneva: World Health Organization; 2016.

16. World Health Organization. World Health Statistics 2012. Part III: global health indicators. Geneva: World Health Organization; 2012.

17. Government of the Federal Democratic and Republic of Ethiopia: National Nutrition Program June 2013-June 2015.
18. Ethiopia National Expanded Programme on Immunization. Comprehensive Multi- Comprehensive Multi-year Plan 2016 year plan 2016 year plan 20162020 federal ministry of health. Addis Ababa; 2015.

19. Habtemariam MK, Semegn ST. Setting health sector priorities: a brief overview of ethiopia's experience. Cost Eff Resour Alloc. 2018;16(1):46.

20. Kondrup JE, Allison SP, Elia M, Vellas B, Plauth M. ESPEN guidelines for nutrition screening 2002. Clin Nutr. 2003;22(4):415-21.

21. Hailemariam $H$, Singh $P$, Fekadu T. Evaluation of mini nutrition assessment (MNA) tool among community dwelling elderly in urban community of Hawassa city, Southern Ethiopia. BMC Nutrition. 2016;2(1):11.

22. CSA. Population projections for Ethiopia: 2007-2037. Federal Democratic Republic of Ethiopia, Population Census Commission Addis Ababa 2013.

23. Tessfamichael D, Gete AA, Wassie MMJR, write. High prevalence of undernutrition among elderly people in Northwest Ethiopia: a cross sectional study 2014;244:32.2

24. Guigoz Y, Vellas B, Garry PJ. Assessing the nutritional status of the elderly: the mini nutritional assessment as part of the geriatric evaluation. Nutr Rev. 1996;54(1):S59-65.

25. Yesavage JA, Brink TL, Rose TL, Lum O, Huang V, Adey M, Leirer VO. Development and validation of a geriatric depression screening scale: a preliminary report. J Psychiatr Res. 1982;17(1):37-49.

26. Wong MM, So WK, Choi KC, Cheung R, Chan HY, WH J, Sit BH, Li F, Lee TY, Ngai CT, Chair SY. Prevalence of malnutrition and its associated factors among home living older adults in Hong Kong.

27. Damião R, Santos ÁD, Matijasevich A, Menezes PR. Factors associated with risk of malnutrition in the elderly in South-Eastern Brazil. Rev Bras Epidemiol. 2017;20:598-610.

28. Adhana ZK, Tessema GH, Getie GA. Prevalence of under nutrition and associated factors among people of old age in debre markos town, northwest ETHIOPIA; 2015.

29. Vrdoljak D, Marković BB, Kranjčević K, Vučak J, Lalić DI. Short form of the mini nutritional assessment is a better proxy for nutritional status in elderly than the body mass index: cross-sectional study. Health Aging Res. 2014;6(3):1.

30. Goodpaster BH, Park SW, Harris TB, et al. The loss of skeletal muscle strength, mass, and quality in older adults: the health, aging and body composition study. J Gerontol A Biol Sci Med Sci. 2006;61:1059-64.

31. Gallagher D, Ruts E, Visser M, Heshka S, Baumgartner RN, Wang J, Pierson RN, Pi-Sunyer FX, Heymsfield SB. Weight stability masks sarcopenia in elderly men and women. Am J Physiol Endocrinol Metab. 2000;279(2):E366-75.

32. Naidoo I, Charlton KE, Esterhuizen TM, Cassim B. High risk of malnutrition associated with depressive symptoms in older South Africans living in KwaZulu-Natal, South Africa: a cross-sectional survey. J Health Popul Nutr. 2015;33(1):19.

33. Damayanthi HD, Moy FM, Abdullah KL, Dharmaratne SD. Health related quality of life and its associated factors among community-dwelling older people in Sri Lanka: a cross-sectional study. Arch Gerontol Geriatr. 2018;76:215-20.

34. Boscatto EC, Duarte MD, Coqueiro RD, Barbosa AR. Nutritional status in the oldest elderly and associated factors. Rev Assoc Méd Bras. 2013;59(1):40-7.

35. Fent T. Department of Economic and Social Affairs, population division, United Nations expert group meeting on social and economic implications of changing population age structures. Eur J Population. 2008;24(4):451-2.

36. Leslie W, Hankey C. Aging, nutritional status and health. InHealthcare Multidisciplinary Digital Publishing Institute, 2015. 3, 3, 648-658.

37. Soundararajan AS, Mathew AC, Nanjuudan R, Ganesh A. Association of Geriatric Syndromes with malnutrition among elderly. Int J Med Res Health Sci. 2017;6(5):14-8.

38. Park $\mathrm{YH}$, Suh EE. The risk of malnutrition, depression, and the perceived health status of older adults. J Korean Acad Nurs. 2007;37(6):941-8.

39. Link BG, Phelan J. Social conditions as fundamental causes of disease. J Health Soc Behav. 1995:80-94.

\section{Publisher's Note}

Springer Nature remains neutral with regard to jurisdictional claims in published maps and institutional affiliations. 